\title{
In-vivo Kinematics of the Cervical Spine in Frontal Sled Tests
}

\author{
Christoph Dehner ${ }^{1}$, Sylvia Schick ${ }^{2}$, Wolfram Hell ${ }^{2}$, Peter Richter ${ }^{1}$, Michael Kraus $^{1}$ \& Michael Kramer ${ }^{1}$ \\ ${ }^{1}$ Department for Trauma, Hand, Plastic and Reconstructive Surgery, University of Ulm, Ulm, Germany \\ ${ }^{2}$ Institute for Legal Medicine, Ludwig Maximilians University of München, München, Germany \\ Correspondence: Christoph Dehner, Department for Trauma, Hand, Plastic and Reconstructive Surgery, \\ University of Ulm, Albert-Einstein-Allee 23, Ulm 89081, Germany. Tel: 49-731-5000. E-mail: \\ christoph.dehner@uniklinik-ulm.de
}

Received: December 17, 2012 Accepted: February 16, 2013 Online Published: February 18, 2013

doi:10.5539/gjhs.v5n3p115 URL: http://dx.doi.org/10.5539/gjhs.v5n3p115

\begin{abstract}
The description of cervical spine motion and the risk to sustain a cervical spine injury in traffic accidents is mainly based on rear-end collisions. The knowledge about frontal collisions is comparable low. Therefore the objective of this exploratory study was, to describe the in-vivo cervical spine motion and acceleration during simulated frontal sled collisions and to identify sequences of motion in which the risk of injury is increased.

A frontal collision with a speed change of $10.2 \mathrm{~km} / \mathrm{h}$ was simulated in a sled test with ten volunteers. Cervical spine kinematics was assessed by the simultaneous analysis of the angular head motion and acceleration as well as the simultaneous analysis of the relative motion and acceleration between the head and the first thoracic vertebral body.
\end{abstract}

The motion sequence was divided into five phases. The combination of peak values of the angular head acceleration to ventral and the relative horizontal head acceleration to dorsal between the time period of $90 \mathrm{~ms}$ and 110ms (early flexion phase) included - potential injury generating - shear forces. Although a hyperflexion (late rebound phase) as injury pattern didn't occur, dorsal soft tissue injuries due to eccentric muscle-sprain could not be ruled out completely.

In conclusion the study showed under simulated test conditions that during the early flexion phase and the late rebound phase, acceleration and movement pattern occur that could lead to cervical spine injuries.

Keywords: frontal impact, cervical spine kinematics, volunteer sled test, risk of injury

\section{Introduction}

Since Gay and Abbott (1953) first described the whiplash phenomenon, the mechanism, which causes the cervical spine injuries subsequent to car-to-car collisions has been intensively explored. Throughout the last twenty years, cervical spine motion and intersegmental applied forces have been intensively analyzed in post mortem human spine specimens and volunteer tests, focusing on rear-end collisions (Cholewicki et al., 1998; Luan et al., 2000; Panjabi et al., 1998). These studies have identified an initial transient S-shape of the cervical spine in response to a rear-end impact, in which the more cranial motion segments undergo flexion, coupled with hyperextension in the more caudal segments.

By comparison, the mechanisms of injury operating during frontal collisions remain largely unstudied (Kumar, Narayan, \& Amell, 2003). The first systematic evidence of damage to structures in the cervical spine after frontal collisions was reported by Bucholz, Burkhead, and Graham (1979) from post-mortem examinations. Subjects sustaining high-impact trauma exhibited ruptures of the dorsal ligaments. Further studies of post-mortem human subjects (PMHS) sustaining frontal collisions have confirmed injury to dorsal ligament structures (Crowell, Shea, \& Edwards, 1993).

Panjabi et al. (2004) were able to further characterize these injuries in PMHS sustaining frontal collisions. After the simulated frontal collision they showed in an anatomical investigation that the greatest elongations of both the supra- and interspinous ligaments and of the ligamentum flavum occurred at the cervical level C3/4 as hint for the main location of the injury. These biomechanical studies were based on a hyperflexion motion of the cervical spine occurring during frontal collisions. 
The first in-vivo frontal collision tests were conducted between 1970 and 1990 and predominantly involved military personnel in studies of strain in aircraft carrier pilots (Ewing, Thomas, Lustick, \& Becker, 1975; Grunsten, Gilbert, $\&$ Mawn, 1989). The simulated changes in velocity $(\Delta \mathrm{V})$ of the vehicle were relatively high with an average $\Delta \mathrm{V}$ of $40-50 \mathrm{~km} / \mathrm{h}$. As low-velocity simulations are defined with a threshold lower than $15 \mathrm{~km} / \mathrm{h}$, these tests could not be considered as low-velocity simulations in the strict sense.

Subsequent in-vivo studies of frontal collision events have similarly failed to provide an exact characterization of the biomechanical mechanisms involved in these occurrences (Kullgren, Krafft, Nygren, \& Tingvall, 2000; Larder, Twiss, \& Mackay, 1995). In an analysis of real frontal crash events in Sweden documented by an on-board black box, Kullgren et al. (2000) reported that with an average $\Delta \mathrm{V}$ of $22 \mathrm{~km} / \mathrm{h}$ frontal collisions were associated with injury thresholds that were twice as high compared with rear impacts. The authors explained this difference biomechanically by the simultaneous forward motion of the torso and head over a significantly longer distance before reaching the seatbelt. Further biomechanical studies to more precisely characterize the kinematics of the cervical spine during frontal collisions were not identified in the literature.

This paucity of data is astonishing given the fact that frontal collisions are cited in the literature as the most frequent type of motor vehicle accident, making up about $60 \%$ of these occurrences ( $\mathrm{O}^{\prime}$ Neil, Lund, Preuss, \& Zuby, 1994). In addition, these accidents are the cause about one-third of all cervical spine injuries (Kullgren et al., 2000). Thus, the exact kinematic behaviour of the cervical spinal column during crash situations has been adequately described only for rear collisions. This explains why it is still unknown which time period during the crash situation in frontal collision is associated with the highest risk of cervical spine injury. Therefore the objective of this exploratory study was, to describe the in-vivo cervical spine motion and acceleration during simulated frontal sled collisions and to identify sequences of motion in which the risk of injury is increased.

\section{Methods}

\subsection{Subjects}

The work has been approved by the local ethics committee. The people were invited to participate in the study by an invitation letter, which was distributed in the University of Ulm. Thereby the intended experiment was outlined. In case of interest to participate in the study a contact phone number was given. $\mathrm{N}=13$ people responded to the invitation to participate. The participants were asked about their medical history. Additionally an orthopaedic surgeon performed a clinical examination. The clinical examination consists of the investigation of muskuloskeletal and osseous spinal triggerpoints, the neurological examination of the peripheral nervous system and the determination of the range of motion of the spine. Exclusion criteria were a history of whiplash injury of the cervical spine, neurological or psychiatric disease, functional impairments of the cervical spine or cervical spine pain. $\mathrm{n}=10$ participants could be selected after proofing the exclusion criteria. The participants were informed about the exact test procedure and gave written consent to participate in the study.

\subsection{Experimental Design}

For the frontal collision simulation we used a standard automobile seat (VW Passat, 2000 model, VW corporation, Wolfsburg, Germany) anchored to a sled platform (Figure 1). The seat sled was accelerated over a length of 20 meters towards the fixed iron barrier. With each participant one sled test was performed.

Measurement of the sled acceleration was performed using a sensor (Endevco 2262, +/- 200g, uniaxial x-direction, CFC 60, Endevco Corporation, San Juan Capistrano, USA). The sled acceleration is characterized by a triangular impulse. The calculation of $\Delta \mathrm{v}$ was performed on the basis of the CFC180 filtered sled acceleration. The mean acceleration of the seat sled was $2.68 \mathrm{~g}$ and the mean $\Delta \mathrm{v}$ was $10.2 \mathrm{~km} / \mathrm{h}$ (Table 1).

Table 1. Characteristics of the sled test acceleration $(\mathrm{N}=10)$

\begin{tabular}{lllll}
\hline & Mean sled acceleration $[\mathrm{g}]$ & Maximal sled acceleration $[\mathrm{g}]$ & Duration $[\mathrm{ms}]$ & $\Delta \mathrm{v}[\mathrm{km} / \mathrm{h}]$ \\
\hline Minimum & 2.45 & 3.57 & 100 & 9.9 \\
Maximum & 3.27 & 4.89 & 110 & 12.7 \\
Median & 2.68 & 4.00 & 110 & 10.2 \\
Mean & 2.76 & 4.05 & 106 & 10.4 \\
Standard deviation & 0.21 & 0.35 & 5 & 0.8 \\
\hline
\end{tabular}

$\Delta v$ : change of velocity 
After positioning the subjects on the test sled, head restraints were adjusted to the best possible vertical position, which means that the upper edge of the head-restraint was aligned with the vertex of the head of each subject (Figure 1). A horizontal adjustment was not possible. The initial horizontal distance from the head to the head restraint ranged from 40 to $90 \mathrm{~mm}$ (median $60 \mathrm{~mm}$ ). In addition, all subjects were secured with a three-point seat belt in passenger position. The backrest was fixed and checked after each test for remaining in $25^{\circ}$ backrest angle to seat cushion.

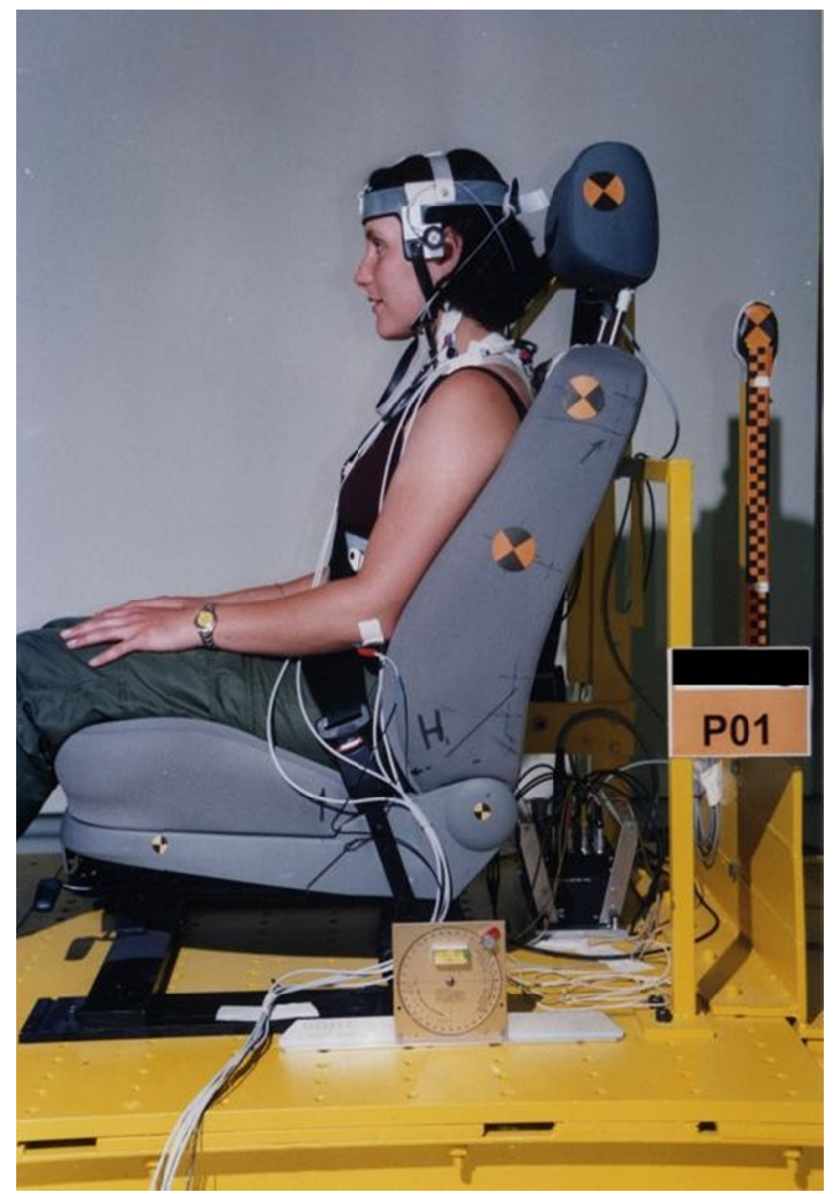

Figure 1. Side view of test sled

\subsection{Measurement Technique, Data Recording and Processing}

The data mentioned below were recorded for all subjects from $-800 \mathrm{~ms}$ to $+800 \mathrm{~ms}$, with " 0 " defining the time of the trigger response. Data recording and processing according to Society of Automotive Engineers ((SAE) J211/1; 1995) was performed with Diadem ${ }^{\circledR} 8.0$ (National Instruments Germany GmbH, Munich, Germany).

\subsubsection{Motion Data and Visual Documentation}

The experiments were recorded with a stationary LOCAM high speed camera (Visual Instrumentation Corporation, USA) and subsequent digitized with 100 images/s. The motion data were documented based on markings of the center of gravity of the head (surface projection ca. $1.5 \mathrm{~cm}$ ventrally and cranially to the most cranial point of the external acoustic meatus), the Frankfort plane (defined as the inferior margin of the osseous orbit and the upper margin of the external ear canal) and the first thoracic vertebra. Tracking of the target in the digitized film was performed in $10 \mathrm{~ms}$ steps for the first $300 \mathrm{~ms}$. The motion was calculated on the basis of the sled-related coordinate system (x-axis (positive forwards), the y-axis (positive to the left) and the positive z-axis extends perpendicularly upwards). The data were smoothed prior to further processing, using a third order spline which is at least square error optimized (Woltring, 1986). 


\subsubsection{Accelerations}

To measure the angular head acceleration also the rotation rate sensor (Endevco 7302, 5000 rad $/ \mathrm{sec}^{2}$, piezoresistive (Endevco Corporation, San Juan Capistrano, USA)) was fixed in a position close to the projected centre of gravity of the head.

In order to measure the $\mathrm{T} 1$ acceleration (acceleration of the first thoracic vertebral body), a two-axial linear accelerometer (Endevco 7264, +/- 200g (Endevco Corporation, San Juan Capistrano, USA)) was mounted on a pliable metal plate, which was padded with tape, adjusted to the contour of the subject's back and attached directly to the skin above the spinal process of the first thoracic vertebra. The starting position of the T1 sensor above the spinal process of the first thoracic vertebral body defined the sensor-related coordinate system. The positive x-axis pointed in ventral direction, perpendicular to the body surface, and the positive z-axis, which was perpendicular to the $\mathrm{x}$-axis pointed in cranial direction. The accelerations are not compensated for gravity, as they are automatically set to zero prior to the test.

The measurement of the horizontal head acceleration was performed using a three-axial linear accelerometer MSC 123 sensor (+/- 100g (Micro-epsilon Messtechnik GmbH \& Co. KG, Ortenburg, Germany)). The accelerometer was attached to the subject via a head harness with which the sensor could be positioned as close as possible to the projected centre of gravity of the head. Analogue to the motion data the anatomical head coordinate system was based on the Frankfort-plane. The relative acceleration between the head and T1 in x-direction was calculated from these accelerations.

\subsection{Analysis}

Due to the high costs for the performance of each experimental sled test and the given financial budget for the study procedure, the maximal sample size of ten participants was already fixed at the beginning of the study. Therefore no power analysis was performed. The analysis of the motion and acceleration curves was performed descriptively for each participant. Generally, the start of acceleration or motion was defined as the time at which $10 \%$ of the subsequent maximum/minimum was reached or the zero-crossing when a change of sign occurred. The following biomechanically relevant parameters of the motion and acceleration curves were ascertained chronologically concerning the amplitudes and the time of occurrence (Table 2). For final data presentation the statistical values minimum, maximum, median, mean and standard deviation - was calculated out of all 10 samples. The definition of the motion phases was performed on the basis of the time of occurrence of the calculated motion parameters.

Table 2. Definition of biomechanically relevant kinematic events in the motion and acceleration curves

\begin{tabular}{ll}
\hline Parameter & Definition \\
\hline $\begin{array}{l}\text { Angular head movement } \\
\text { Beginning of head flexion }\end{array}$ & $10 \%$ of the maximum \\
Maximal head flexion & Maximum \\
$\begin{array}{l}\text { Relative horizontal head movement } \\
\text { Beginning of ventral head translation }\end{array}$ & $10 \%$ of the maximum \\
Maximal ventral head translation & Maximum \\
$\begin{array}{l}\text { Angular head acceleration } \\
\text { Beginning of ventral angular head acceleration } \\
\text { Maximal ventral angular head acceleration } \\
\text { Beginning of dorsal angular head acceleration } \\
\text { Maximal dorsal angular head acceleration }\end{array}$ & $10 \%$ of the maximum \\
Relative horizontal head acceleration & Maximal positive peak \\
Beginning of dorsal horizontal head acceleration & Zero crossing \\
Maximal dorsal horizontal head acceleration & Maximal negative peak \\
Minimal dorsal horizontal head acceleration & Relative minimal negative peak \\
\hline
\end{tabular}




\section{Results}

\subsection{Subjects}

Ten subjects (seven men, three women) aged 20 to 47 years (median: 35 years) without prior structural injuries to the spine participated in the study. Subjects' height ranged from 170 to $191 \mathrm{~cm}$ (median: $180 \mathrm{~cm}$ ), their mass was 61-110 kg (median: $83.5 \mathrm{~kg}$ ), their neck circumference ranged from 26 to $49 \mathrm{~cm}$ (median: $40 \mathrm{~cm}$ ) and their thorax circumference ranged from 80 to $112 \mathrm{~cm}$ (median: $102 \mathrm{~cm}$ ).

\subsection{Description of the Motion Phases}

The motion sequence was divided into five phases (Table 3 and Figure 2). This was reproducible for all subjects. In all subjects, the maximal motion amplitudes during the frontal collision fell within the physiological limits determined at the beginning of the study (Table 4$)$. In the latency phase $(0 \mathrm{~ms}-44 \mathrm{~ms})$ the head initially remained in its baseline position. In the translation phase $(44 \mathrm{~ms}-68 \mathrm{~ms})$ the ventral translation of the head began without a rotational component after a median of $44 \mathrm{~ms}(25 \mathrm{~ms}-64 \mathrm{~ms})$. In the flexion phase $(68 \mathrm{~ms}-196 \mathrm{~ms})$ additionally to the isolated translation ventral flexion of the head starts after a median of $68 \mathrm{~ms}(60 \mathrm{~ms}-80 \mathrm{~ms})$. A head to headrest contact did not take place at any time. After a median of $196 \mathrm{~ms}(175-233 \mathrm{~ms})$ the maximal ventral head translation (median: $112 \mathrm{~mm}, 62-132 \mathrm{~mm}$ ) was reached (Table 4). During the rebound phase I (196ms-223ms) the head reached its maximal head flexion (median: $\left.36.2^{\circ}, 21.2-48.2^{\circ}\right)$. In the rebound phase II $(223 \mathrm{~ms}-300 \mathrm{~ms})$ the maximal ventral translational motion of the head and the head flexion were both decreasing slightly. These results were reproducible for all subjects.

Table 3. Definition of the motion phases on the basis of the most relevant motion parameters

\begin{tabular}{ll}
\hline Motion phase & Parameter \\
\hline Latency phase & Beginning of the sled acceleration \\
End & Beginning of the ventral head translation \\
Translation phase & Beginning of the ventral head translation \\
Beginning & Beginning of the head flexion \\
End & Beginning of the head flexion \\
Flexion phase & Time of maximal ventral head translation \\
Beginning & \\
End & Time of maximal ventral head translation \\
Rebound phase I & Time of maximal head flexion \\
Beginning & \\
End & Time of maximal head flexion \\
Rebound phase II & End of data presentation (300ms) \\
Beginning & \\
End &
\end{tabular}




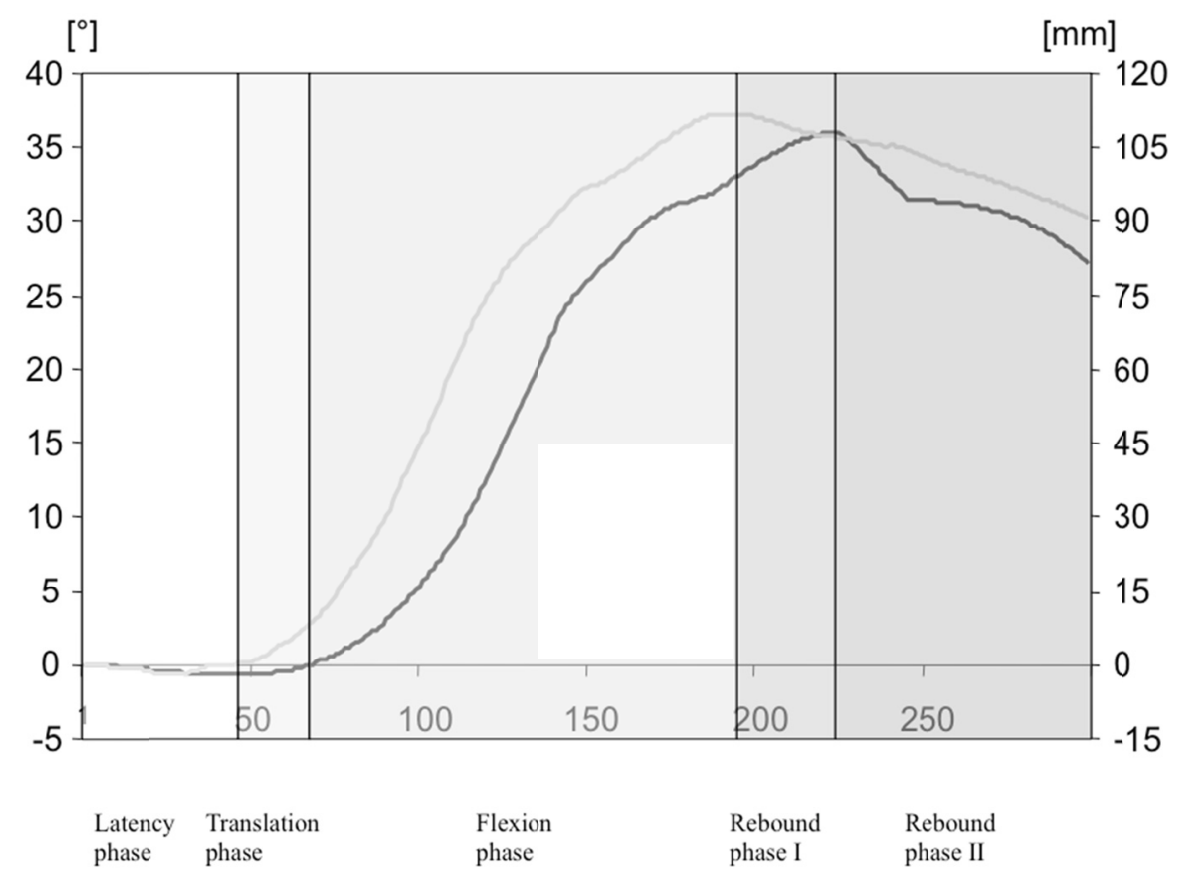

Figure 2. Median curves of the motion parameters and definition of the motion phases on the basis of the most relevant motion parameters

Black curve: relative horizontal head movement [mm]; grey curve: angular head movement $\left[{ }^{\circ}\right]$

\subsection{Analysis of Kinematic Phases in Relation to Motion and Acceleration Parameters}

Analysis of all four parameters (angular head movement, angular head acceleration, relative horizontal head movement and relative horizontal head acceleration) permits a more exact impression of force impact and time of its occurrence (Tables 4 and 5, Figure 3). The following results were reproducible for all subjects.

Table 4. Amplitudes of the Motion and Acceleration Parameters as defined in Table 2

\begin{tabular}{llllll}
\hline Parameter & Minimum & Maximum & Median & Mean & Standard deviation \\
\hline $\begin{array}{l}\text { Angular head movement }\left[^{\circ}\right] \\
\text { Maximal head flexion }\end{array}$ & 21.2 & 48.2 & 36.2 & 35.0 & 7.1 \\
$\begin{array}{l}\text { Relative horizontal head movement }[\mathrm{mm}] \\
\text { Maximal ventral head translation }\end{array}$ & 62 & 132 & 112 & 110 & 20 \\
Angular head acceleration $\left[\mathrm{rad} / \mathrm{s}^{2}\right]$ & & & & & \\
Maximal ventral angular head acceleration & 110 & 367 & 177 & 207 & 69 \\
Maximal dorsal angular head acceleration & 231 & 425 & 260 & 308 & 82 \\
Relative horizontal head acceleration $[\mathrm{g}]$ & & & & & \\
Maximal dorsal horizontal head acceleration & 4.1 & 6.2 & 5.0 & 5.1 & 0.6 \\
Minimal dorsal horizontal head acceleration & 0.4 & 1.7 & 1.2 & 1.1 & 0.4 \\
\hline
\end{tabular}


Table 5. Time of occurrence of the motion and acceleration parameters in [ms] as defined in Table 2

\begin{tabular}{|c|c|c|c|c|c|}
\hline Parameter & Minimum & Maximum & Median & Mean & Standard deviation \\
\hline \multicolumn{6}{|l|}{ Angular head movement } \\
\hline Beginning of head flexion & 60 & 80 & 68 & 69 & 6 \\
\hline Time of maximal head flexion & 192 & 239 & 223 & 212 & 19 \\
\hline \multicolumn{6}{|l|}{ Relative horizontal head movement } \\
\hline Beginning of ventral head translation & 25 & 64 & 44 & 43 & 12 \\
\hline Time of maximal ventral head translation & 175 & 233 & 196 & 203 & 21 \\
\hline \multicolumn{6}{|l|}{ Angular head acceleration } \\
\hline Beginning of ventral angular head acceleration & 21 & 46 & 31 & 32 & 8 \\
\hline Time of maximal ventral angular head acceleration & 73 & 138 & 96 & 102 & 21 \\
\hline Beginning of dorsal angular head acceleration & 120 & 144 & 131 & 131 & 7 \\
\hline Time of maximal dorsal angular head acceleration & 144 & 164 & 149 & 152 & 6 \\
\hline \multicolumn{6}{|l|}{ Relative horizontal head acceleration } \\
\hline Beginning of dorsal horizontal head acceleration & 26 & 75 & 49 & 53 & 16 \\
\hline Time of maximal dorsal horizontal head acceleration & 97 & 134 & 106 & 108 & 10 \\
\hline Time of minimal dorsal horizontal head acceleration & 143 & 168 & 156 & 158 & 7 \\
\hline
\end{tabular}




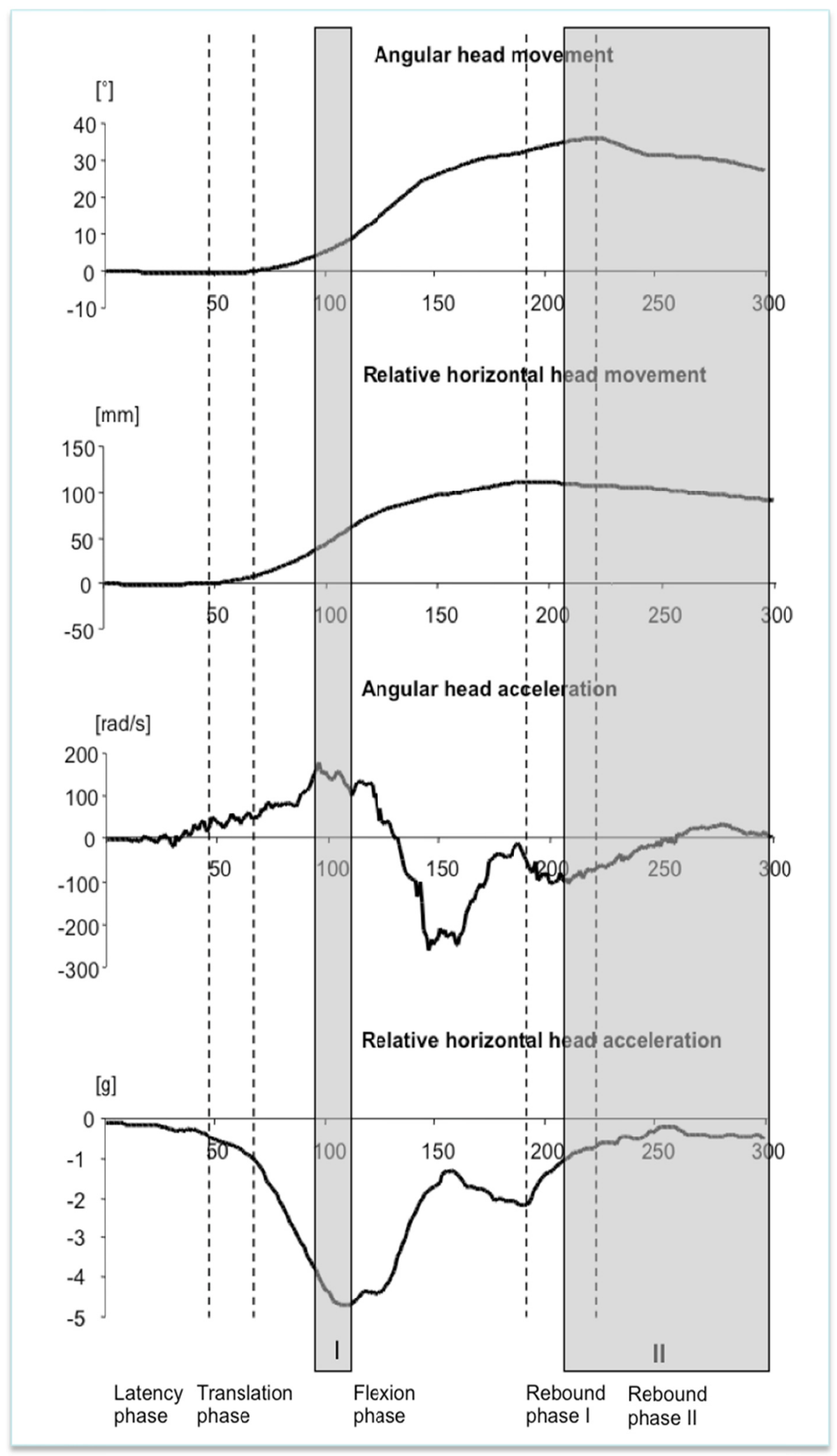

Figure 3. Median curves of the motion and acceleration parameters

Grey box I: Time period between $90 \mathrm{~ms}$ and $110 \mathrm{~ms}$ with maximal contrary acting forces; Grey box II: Parallel deceleration of head flexion and ventral head translation 
In the latency phase $(0 \mathrm{~ms}-44 \mathrm{~ms})$, initially isolated ventral angular head acceleration occurred after a median of $31 \mathrm{~ms}(21-46 \mathrm{~ms})$. In the translation phase $(44 \mathrm{~ms}-68 \mathrm{~ms})$ the relative horizontal head acceleration started in dorsal direction after a median of $49 \mathrm{~ms}(26-75 \mathrm{~ms})$. There is only a slight relative ventral translation movement and, consequently, the cervical spine is almost in its initial position.

In the flexion phase $(68 \mathrm{~ms}-196 \mathrm{~ms})$ the maximal braking effect of the seat belt occurred after a median of $90 \mathrm{~ms}$ (81ms-99ms). As the horizontal head movement had been slowed down over the whole flexion phase (maximal deceleration - median: 106ms; 97ms-134ms; minimal deceleration - median: $156 \mathrm{~ms}$; 143ms-168ms), the head flexion was firstly accelerated (median: $96 \mathrm{~ms} ; 73 \mathrm{~ms}-138 \mathrm{~ms}$ ) until a deceleration process after a median of $131 \mathrm{~ms}$ $(120 \mathrm{~ms}-144 \mathrm{~ms})$ was initiated. Therefore in the time period between $90 \mathrm{~ms}$ and $110 \mathrm{~ms}$ maximal contrary acting forces could be found (grey box I, Figure 3). In this time period the ventral angular head acceleration (median: $177 \mathrm{rad} / \mathrm{s}^{2}, 110-377 \mathrm{rad} / \mathrm{s}^{2}$ ) and the dorsal horizontal head acceleration (median: 5.0g, 4.1-6.2g) reached their peak values. This was followed by the events of maximal dorsal angular head acceleration (median: 260 $\mathrm{rad} / \mathrm{s}^{2}$, $\left.231-425 \mathrm{rad} / \mathrm{s}^{2}\right)$ after a median of $149 \mathrm{~ms}(144 \mathrm{~ms}-164 \mathrm{~ms})$ and the minimum of dorsal horizontal head acceleration (median: $1.2 \mathrm{~g}, 0.4-1.7 \mathrm{~g})$ after a median of $156 \mathrm{~ms}(143 \mathrm{~ms}-168 \mathrm{~ms})$.

In the rebound phase I and II (196ms-300ms), the parallel deceleration of head flexion and ventral head translation occurred. In this phase, there were constant but low acceleration values over a long period still acting (grey box II, Figure 3). After the maximal ventral translation (median: $112 \mathrm{~mm}, 62-132 \mathrm{~mm}$ ) and the maximal flexion amplitude (median: $36.2^{\circ}, 21.2-48.2^{\circ}$ ) were reached, a slight backwards movement occurred.

\section{Discussion}

Yet, for the improvement of car occupant safety systems, it is important to produce data that are related as closely as possible to the in-vivo situation (Kaneoka, Ono, Inami, \& Hayashi, 1999). As the data resulting from cadaver models are limited in their significance for the in-vivo situation, volunteer tests are necessary. While volunteer tests capture actual cervical spine kinematics, they are limited by the fact that the forces acting on the cervical spine can only be determined approximately. Direct force measurements are not feasible and this requires reference to indirect measurement parameters in the form of acceleration data (Matsushita et al., 1994).

Up to now, inadequate use has been made of sled tests with human subjects in the low velocity range for the purpose of investigating the kinematic processes and injury risk associated with frontal collision. As a result, the ability to compare the results of the present study with previous reports in the literature is limited. The present study described the frontal impact event at a $\Delta \mathrm{V}$ of $10.2 \mathrm{~km} / \mathrm{h}$ on the basis of the recorded motion and acceleration data in volunteers. The parallel analysis of the angular head acceleration and the relative horizontal acceleration of the head shows that the two components of acceleration do not operate simultaneously.

The latency phase begun with early ventral angular head acceleration without a relative horizontal head acceleration. After that a horizontal acceleration of $\mathrm{T} 1$ in ventral direction with a simultaneous relative dorsal acceleration of the head rose up while the ventral angular acceleration of the head was ongoing. While the study of Kumar et al. (2003) provided no motion data, the onset of the resulting head acceleration at a sled acceleration of $1.4 \mathrm{~g}$ was reported at $35.6 \mathrm{~ms}$. These data correspond well with the findings of the present study, with measured onset of ventral head acceleration at $31 \mathrm{~ms}$ and of dorsal horizontal acceleration of the head at $49 \mathrm{~ms}$. The result of this was, first, a relative ventral translation of the head without rotational component, which is secondly accomplished by a flexion movement of the head. Up to this point the reacting forces were comparable low, so that no relevant injury risk could be stated

Distinct from rear collisions, dorsal translation or extension movements did not occur at any point in time and could thus be excluded as causes of injury. There was also no contact between the head and the headrest, which confirmed the assessment of Walz (1994) that the headrest plays no role in frontal collisions.

After that the described acceleration pattern was ongoing, reaching peak values between the time period of $90 \mathrm{~ms}$ and $110 \mathrm{~ms}$. As the amplitude of the relative horizontal head acceleration corresponded to the peak values during a rear-end collision, the peak values of the angular acceleration rose up to threefold compared to the rear-end collision (Dehner et al., 2007). The comparable peak values of the head acceleration were in the frontal sled test study of Deng, Begeman, Yang, Tashman, and King (2000) with $6 \mathrm{~g}$ to15g even higher. This fact and the above mentioned narrow time-corridor illustrates that the reacting forces reached in this time period an unfavourable constellation. Thereby the angular head acceleration could be interpreted as distraction force of the dorsal structures and compression force of the ventral structures of the cervical spine, whereas the relative horizontal acceleration of the head represented shear forces in dorsal direction at the same time. The combination of compression forces in the ventral structures of the cervical spine and dorsal directed shear forces had been assumed to be associated with a high potential for causing injury to the discs (Ito et al., 2005). However, as the head has not yet reached a 
significant deflection, injury mechanisms such as stretching of dorsal ligaments or capsules are unlikely. Further in-vivo data, especially with regard to the chronological occurrence of peak accelerations, are not available for comparison.

In this study the maximal braking effect of the seat belt occurred after a median of $90 \mathrm{~ms}(81 \mathrm{~ms}-99 \mathrm{~ms})$, close before the above described risky time corridor. Kullgren et al. (2000) considered the deceleration of the body in its forward motion by the onset of the seat belt effect to be the main risk factor. In addition Siegmund, Chimich, Heinrichs, DeMarco, and Brault (2005) demonstrated that maximum motion and acceleration vary significantly in relation to the attachment and tension of the seat belt. For example, with lax seat belt tension, there was an increase in both ventral motion and ventral acceleration amplitudes of the thorax. By contrast, Walz (1994) postulated that, in the absence of head impact and limited vehicular damage, cervical spine injury would occur only in subjects with pre-existing damage to the cervical spine or significant head rotation during the crash event.

In the rebound phase II the risk of injury must be assessed together with the increasing ventral motion of the head. Unlike during the previous movement, external force applications resulting in a deceleration of the head were mainly absent. Therefore deceleration forces have to be extinguished by active muscle tension or increasing of the soft tissue resistance like the stretched dorsal ligamentous and capsular structures. Panjabi (1992) found out that at the end of the physiological range of motion - in the elastic zone of ligaments - only a small force increase is necessary to cause plastic distortion. Larder et al. (1995) therefore assumed that in frontal collision without a head contact the flexion movement of the head solely causes the injury. The maximum median flexion of the head observed in the present study was $28.9^{\circ}$, which remains within the normal physiological range of motion. Keeping in mind the assumptions of McPherson, Schorck, and Faulkner (1996) and Kumar, Ferrari, and Narayan (2005), however, the combination of such injury with an excessive increase in muscle activity cannot be ruled out as a cause of patients' complaints. This relationship should be addressed in further studies focusing on muscular reaction time and its interaction with cervical spine kinematics.

The results of the sled tests performed in this study are simulating a passenger position, which could be different of the driver position in the case of a direct impact due to the steering wheel. If no direct impact with the steering wheel occurs, minor changes in the kinematic behaviour could not be ruled out due to the different position of the arms and a possible stabilizing effect of the torso. Up to now the investigation of differences of the kinematic behaviour between the driver and passenger position in frontal collisions has not performed. As further limitation of the study the existence of a small sample size has to be mentioned. This is caused by the quite complex and expensive experimental setup, which didn't allow larger test series. As the maximal sample size of ten participants was already fixed at the beginning of the study, no power analysis was performed. Nevertheless this fact leads to a reduction of the validity of the study results and a lack of power for generalizing the conclusions. Therefore the data of this study are descriptive and have to be confirmed in further studies. Until then the data of this study have to be assessed as preliminary results.

\section{Conclusions}

The study shows that during the early flexion phase and the late rebound phase kinematic constellations exist that could lead to cervical spine injuries. In the flexion phase contrary acceleration applications could lead to ventral shear injuries of the disco-ligamentous structures. As important study result the maximal ventral head movement did not exceed the physiologic range of motion excluding a hyperflexion movement as key injury pattern. Nevertheless the occurrence of dorsal soft tissue injuries due to eccentric muscle-sprain in the late rebound could not be ruled out completely.

\section{Acknowledgements}

The experiments comply with the current laws of Germany and were performed with approval of the local ethics board. No commercial party having a direct financial interest in the results of the research supporting this article has or will confer a benefit upon the authors or upon any organization with which the authors are associated. 


\section{References}

Bucholz, R. W., Burkhead, W. Z., \& Graham, W. (1979). Occult cervical spine injuries in fatal traffic accidents. J Trauma, 19(10), 768-771. http://dx.doi.org/10.1097/00005373-197910000-00009

Cholewicki, J., Panjabi, M. M., Nibu, K., Babat, L. B., Grauer, J. N., \& Dvorak, J. (1998). Head kinematics during in vitro whiplash simulation. Accid Anal Prev, 30(4), 469-479. http://dx.doi.org/10.1016/S0001-4575(97)00103-6

Crowell, R. R., Shea, M., \& Edwards, W. T. (1993). Cervical injuries under flexion and compression loading. $J$ Spinal Disord, 6(2), 175-181. http://dx.doi.org/10.1097/00002517-199304000-00013

Dehner, C., Elbel, M., Schick, S., Walz, F., Hell, W., \& Kramer, M. (2007). Risk of injury of the cervical spine in sled tests in female volunteers. Clin Biom, 22(6), 615-622. http://dx.doi.org/10.1016/j.clinbiomech.2007.02.004

Deng, B., Begeman, P. C., Yang, K. H., Tashman, S., \& King, A. I. (2000). Kinematics of human cadaver cervical spine during low speed rear-end impacts. Stapp Car Crash J, 44, 171-188.

Ewing, C. L., Thomas, D. J., Lustick, L., \& Becker, E. (1975). The effect of the initial position of the head and neck on the dynamic response of the human head. Paper presented at the 19th Stapp Car Conference, San Diego.

Gay, J. R., \& Abbott, K. H. (1953). Common whiplash injuries of the neck. J.A.M.A., 29(8), 1698-1704. http://dx.doi.org/10.1001/jama.1953.03690180020006

Grunsten, R. C., Gilbert, N. S., \& Mawn, S. V. (1989). The mechanical effects of impact acceleration on the unconstrained humen head and neck complex. Contemporary Orthopaedics, 18(2), 199-202.

Ito, S., Ivancic, P. C., Pearson, A. M., Tominaga, Y., Gimenez, S. E., Rubin, W., \& Panjabi, M. M. (2005). Cervical intervertebral disc injury during simulated frontal impact. Eur Spine J, 14(4), 356-365. http://dx.doi.org/10.1007/s00586-004-0783-4

Kaneoka, K., Ono, K., Inami, S., \& Hayashi, K. (1999). Motion analysis of cervical vertebrae during whiplash loading. Spine, 24(8), 763-769. http://dx.doi.org/10.1097/00007632-199904150-00006

Kullgren, A., Krafft, M., Nygren, A., \& Tingvall, C. (2000). Neck injuries in frontal impacts: influence of crash pulse characteristics on injury risk. Accid Anal Prev, 32(2), 197-205. http://dx.doi.org/10.1016/S0001-4575(99)00096-2

Kumar, S., Ferrari, R., \& Narayan, Y. (2005). Looking away from whiplash: effect of head rotation in rear impacts. Spine, 30(7), 760-768. http://dx.doi.org/10.1097/01.brs.0000157416.09685.e4

Kumar, S., Narayan, Y., \& Amell, T. (2003). Analysis of low velocity frontal impacts. Clin Biomech (Bristol, Avon), 18(8), 694-703. http://dx.doi.org/10.1016/S0268-0033(03)00137-2

Larder, D. R., Twiss, M. K., \& Mackay, G. M. (1995). Neck injury to car occupants using seat belts. Paper presented at the 29th Ann Proc Am Assoc Auto Med, Washington, USA.

Luan, F., Yang, K. H., Deng, B., Begeman, P. C., Tashman, S., \& King, A. I. (2000). Qualitative analysis of neck kinematics during low-speed rear-end impact. Clin Biomech (Bristol, Avon), 15(9), 649-657. http://dx.doi.org/10.1016/S0268-0033(00)00031-0

Matsushita, T., Sato, T. B., Hirabayashi, K., Fujimura, S., Asazuma, T., \& Takatori, T. (1994). X-Ray study of the human neck motiondue to head inertia loading. Paper presented at the 37th Stapp Car Crash Conference, Fort Lauderdale, USA.

McPherson, P. C., Schorck, M. A., \& Faulkner, J. A. (1996). Contraction-induced injury to single fiber segments from fast and slow muscles of rats by single stretches. Am J Physiol., 271(5), 1438-1446.

O' Neil, B., Lund, A., Preuss, C., \& Zuby, D. (1994). Offset frontal impacts - a comparison of real-world crashes with laboratory tests. Paper presented at the 14th ESV Conference, München, Germany.

Panjabi, M. M. (1992). The stabilizing system of the spine. Part II. Neutral zone and instability hypothesis. $J$ Spinal Disord, 5(4), 390-396. http://dx.doi.org/10.1097/00002517-199212000-00002

Panjabi, M. M., Cholewicki, J., Nibu, K., Grauer, J. N., Babat, L. B., Dvorak, J., \& Bar, H. F. (1998). Biomechanics of whiplash injury. Orthopade, 27(12), 813-819. http://dx.doi.org/10.1007/PL00003468 
Panjabi, M. M., Pearson, A., Ito, S., Ivancic, P., Gimenez, S., \& Tominaga, Y. (2004). Cervical Spine Ligament Injury during Simulated Frontal Impact. Spine, 29(21), $2395-2403$. http://dx.doi.org/10.1097/01.brs.0000143173.92241.ab

Siegmund, G. P., Chimich, D. D., Heinrichs, B. E., DeMarco, A. L., \& Brault, J. R. (2005). Variations in occupant response with seat belt slack and anchor location during moderate frontal impacts. Traffic Inj Prev, 6(1), 38-43. http://dx.doi.org/10.1080/15389580590903159

Walz, F. (1994). Biomechanical aspects of injuries of the cervical vertebrae. Orthopade, 23(4), 262-267.

Woltring, H. J. (1986). A Fortran Package for generalized, cross-validatory spline smoothing and differentiation. Adv.Eng.Software, 8(2), 104-113. http://dx.doi.org/10.1016/0141-1195(86)90098-7 